\title{
A utilização de fotografias no ensino-aprendizagem de química
}

\section{The use of photographs in chemistry teaching-learning}

\author{
Laís Perpétuo Perovano ${ }^{1}$; Ana Nery Furlan Mendes ${ }^{2}$
}

1 Mestre em ensino na educação básica, Instituto Federal do Espírito Santo, São Mateus, ES, Brasil laisperovano@hotmail.com / https://orcid.org/0000-0002-9567-3384

2 Doutora em Química, Universidade Federal do Espírito Santo, São Mateus, Espírito Santo, Brasil - ana.n.mendes@ufes.br/ https://orcid.org/0000-0001-6488-5483

Palavras-chave: Aprendizagem significativa. Ensino. Fotografia.

\section{Keywords:}

Meaningful Learning.

Teaching. Photography.
RESUMO: Este trabalho descreve a aplicação de um projeto intitulado "Aqui tem Química", que tem por base a utilização de fotografias para o ensino-aprendizagem de Química. Seu objetivo principal consiste na construção do conhecimento científico, por meio do uso de fotografias, produzidas pelos próprios estudantes. Participaram das atividades 40 alunos, matriculados em uma turma da $1^{\text {a }}$ série do Ensino Médio, turno noturno, de uma Escola Estadual localizada no município de Linhares- ES. O projeto foi desenvolvido no primeiro semestre letivo do ano de 2016 e contemplou 3 fases, sendo elas: (1) fase exploratória, (2) orientação e (3) análise/exposição das fotos. A análise dos dados coletados indicou que a estratégia de ensino utilizada favoreceu o processo de ensino-aprendizagem dos participantes, ampliando as percepções dos discentes em relação a presença da Química no cotidiano. Observou-se que a utilização de metodologias de ensino diferenciadas é fundamental para favorecer a internalização de conceitos científicos.

ABSTRACT: This work describes the application of a project entitled "Aqui tem Química", which is based on the use of photographs for teaching and learning Chemistry. Its main objective is the construction of scientific knowledge through the use of photographs, produced by the students themselves. Forty students participated in the activities, enrolled in a class from the 1st grade of High School, night shift, from a State School, located in the municipality of Linhares-ES, in the first academic semester of the year 2016. The project included 3 phases: (1) exploratory phase, (2) orientation and (3) analysis / exposure of the photos. The analysis of the collected data indicated that the teaching strategy used favored the teaching-learning process of the participants, expanding the students' perceptions regarding the presence of Chemistry in their daily lives. It was observed that the use of differentiated teaching methodologies is fundamental to favor the internalization of scientific concepts. 


\section{INTRODUÇÃO}

Na educação básica muitos alunos relatam dificuldades no aprendizado de Química, não percebendo o significado ou a importância do que estudam para o seu cotidiano. Muitas vezes os conteúdos são trabalhados de forma descontextualizada, tornando-se distantes da realidade, não despertando o interesse e a motivação dos alunos. Além disso, alguns professores de química demonstram dificuldades em relacionar os conteúdos científicos com eventos da vida, priorizando a reprodução do conhecimento, a cópia e a memorização de fórmulas matemáticas, esquecendo muitas vezes de associar a teoria com a prática (LIMA et al., 2014).

De acordo com Dorneles (2015), é necessário que o professor aborde conceitos utilizando metodologias adequadas à aprendizagem atual. Não descartando as aulas teóricas, porém, elas devem ser enriquecidas de maneira que efetivamente ocorra uma aprendizagem a partir do desenvolvimento de habilidades.

Neste contexto, têm sido valorizadas metodologias capazes de estimular à reflexão crítica sobre a ação humana no processo de produção do espaço, de modo que os conteúdos de aula tenham sentido também para atender as questões da vida e não só para responder às exigências curriculares da escola (FURTADO, 2014).

Contrariamente ao modelo tradicional de ensino, defende-se que o ensinoaprendizagem de Química deve basear-se em metodologias que propiciem uma aprendizagem significativa para os estudantes. De acordo com Moreira (2010, p. 2)

\footnotetext{
Aprendizagem significativa é aquela em que ideias expressas simbolicamente interagem de maneira substantiva e não-arbitrária com aquilo que o aprendiz já sabe. Substantiva quer dizer não-literal, não ao pé-da-letra, e não-arbitrária significa que a interação não é com qualquer ideia prévia, mas sim com algum conhecimento especificamente relevante já existente na estrutura cognitiva do sujeito que aprende. Nesse processo, os novos conhecimentos adquirem significado para o sujeito e os conhecimentos prévios adquirem novos significados ou maior estabilidade cognitiva.
}

Atualmente, percebe-se que os alunos mantêm maior interesse aos recursos de comunicação (celular e seus aplicativos), do que no assunto desenvolvido pelo professor. Nesse contexto, a escola deve reconhecer que essa nova geração de alunos vive em um mundo no qual o apelo ao visual, à imagem, é atraente e recorrente, com isso modifica de forma relevante seu modo de ver e compreender a realidade (LEITE, 2015).

Como descrevem Costa e Silva (2015),

$\mathrm{O}$ ato de fotografar está cada vez mais naturalizado em nossa sociedade, os jovens e adolescentes utilizam da fotografia como um hábito rotineiro e fazem $o$ compartilhamento nas redes sociais para expressarem seus cotidianos e suas subjetividades. Fora do contexto profissional, para fotografar não se necessita de equipamentos caros ou sofisticados e nem tão pouco de um conhecimento técnico 
Ensino, Saúde e Ambiente - V13 (1), pp. 344-353, Abr. 2020

aprofundado, tanto que nossos alunos através de seus celulares (smartphones) tem cada vez mais facilidade e acesso ao uso de câmeras fotográficas.

$\mathrm{Na}$ literatura, alguns trabalhos discutem o uso de fotografias para favorecer o ensinoaprendizagem de conceitos científicos relacionados a disciplina de Química. Sana e colaboradores (2016) discutem em sua pesquisa uma estratégia baseada na produção de imagens fotográficas partindo da proposta de montagem e operação de um aparato escolar científico conhecido no meio escolar como Pilha de Daniell.

Cunha (2018), em seu artigo "A Fotografia Científica no Ensino: Considerações e Possibilidades para as Aulas de Química”, descreve algumas atividades didáticas que podem ser realizadas em aulas de Química em dois usos distintos: a fotografia científica observatória e a macrofotografia didática. Os resultados obtidos se mostraram promissores no que se refere ao uso da fotografia para explorar um tema, na observação de atividades experimentais e nas discussões com estudantes imagens presentes em seu livro didático ou na mídia.

Messeder e colaboradores (2019) relatam em sua pesquisa uma intervenção pedagógica em aulas de química, com o objetivo de relacionar o ensino-aprendizagem da tabela periódica a partir do uso de fotografias. Silva e Hussein (2013) descrevem em seu trabalho o uso de fotografias como ferramenta para avaliação da aprendizagem dos conceitos de fenômenos físicos e reações químicas.

Visando uma aprendizagem significativa e utilizando ferramentas tecnológicas de fácil acesso como celular, foi desenvolvido um projeto intitulado "Aqui tem Química". Seu objetivo principal é favorecer o processo de internalização de conceitos científicos a partir da leitura e interpretação de fotografias, produzidas pelos estudantes, proporcionando-lhes uma forma de conhecimento baseada no seu cotidiano. Dessa maneira, buscou-se explorar uma das diversas possibilidades de uso da fotografia em sala de aula, procurando identificar suas potencialidades no processo de ensino-aprendizagem.

\section{METODOLOGIA}

O presente estudo foi desenvolvido considerando o referencial metodológico da pesquisa qualitativa. Guerra $(2014$, p.11) descreve que

\footnotetext{
$\mathrm{Na}$ abordagem qualitativa, o cientista objetiva aprofundar-se na compreensão dos fenômenos que estuda - ações dos indivíduos, grupos ou organizações em seu ambiente ou contexto social -, interpretando-os segundo a perspectiva dos próprios sujeitos que participam da situação, sem se preocupar com representatividade numérica, generalizações estatísticas e relações lineares de causa e efeito.
}

A atividade descrita neste trabalho foi desenvolvida com 40 alunos matriculados na $1^{\mathrm{a}}$ série do Ensino Médio, turno noturno, de uma Escola Estadual localizada no município de 
Linhares - ES. As atividades que constituíram o projeto foram organizadas em 3 fases, sendo elas: (1) fase exploratória, (2) orientação e (3) análise/exposição das fotos.

$\mathrm{Na}$ fase exploratória, os discentes se organizaram em círculos na sala de aula e foram questionados pela professora sobre a presença da Química no cotidiano. Para isso, realizou-se um diálogo dirigido que durou aproximadamente 30 minutos.

Na sequência, iniciou-se a fase de orientação baseada na leitura dinâmica do texto “Química na Sociedade”, disponível no livro Química Cidadã, volume 1. Nesta etapa, cada estudante ficou responsável pela leitura de uma parte do texto, permitindo a participação de todos. Ao término desse momento foi realizado um pequeno debate alicerçado na questão: “Após a leitura do texto podemos dizer que a Química está em todos os lugares?”. Nesta etapa, o tempo de aula utilizado foi cerca de 50 minutos. Ainda nessa aula, os estudantes foram orientados a produzir uma fotografia, retratando a presença da Química no cotidiano em locais como escola, casa e trabalho. Além disso, eles também deveriam descrever o fenômeno representado usando conceitos científicos. Para facilitar a execução da atividade os

estudantes poderiam se organizar em pequenos grupos de até 4 pessoas. A entrega da fotografia (impressa e em formato digital) foi agendada para a semana seguinte, desse modo eles tiveram 7 dias para realizar a atividade.

$\mathrm{Na}$ terceira fase do projeto, as fotografias e a descrição dos fenômenos foram apresentadas à turma, utilizando-se um projetor de imagens. Esta fase foi realizada em 2 aulas, com duração de 50 minutos cada. Posteriormente, os materiais produzidos pelos estudantes foram expostos no mural localizado no pátio da escola.

Para analisar os impactos da metodologia de ensino, ao final das etapas do projeto, os discentes foram convidados a responder duas perguntas para avaliação das atividades. As questões foram impressas e entregues para cada estudante, sendo recolhidas no final da aula.

\section{RESULTADOS E DISCUSSÕES}

Os primeiros resultados referem-se ao retorno positivo dos participantes que se mostraram bem receptivos para o desenvolvimento do projeto. Os resultados obtidos em cada fase do projeto estão descritos a seguir.

\section{FASE EXPLORATÓRIA}

A fase exploratória levou em consideração o conhecimento prévio dos alunos, uma vez que, todos informaram ter estudado Química no ensino fundamental ( $9^{\circ}$ ano). Para 
estimular os alunos a expressarem os seus saberes, os estudantes foram indagados sobre a presença da Química no cotidiano. Algumas respostas encontram-se descritas a seguir.

\footnotetext{
Aluno 1: "Química em casa professora? Não sei, eu lembro que a gente fazia umas experiências no laboratório".

Aluno 2: "Química está nos produtos industrializados ou enlatados, quase tudo que compramos tem Química”.

Aluno 3: "Ela está nos agrotóxicos que matam as pragas das lavouras".

Aluno 4: "A química está no salão de beleza e ajuda as mulheres na hora de alisar os cabelos e fazer selante".

Aluno 5: "Ela está presente nos medicamentos controlados, aqueles que causam dependência".
}

Baseando-se nas respostas apresentadas, acredita-se que os estudantes chegaram ao Ensino Médio com uma percepção limitada em relação a alguns conceitos científicos. Em alguns casos, os discentes demostraram dificuldades para estabelecer uma relação entre a química e o cotidiano, como citado pelos alunos 1 e 2 .

Diante de situações como essa, é importante que o docente, enquanto mediador do processo de ensino-aprendizagem, recorra a metodologias de ensino capazes de promover uma aprendizagem significativa, capazes de favorecer a internalização das informações necessárias ao desenvolvimento e aprendizagem.

\section{FASE DE ORIENTAÇÃO}

Nesta etapa do projeto foi realizada uma leitura e discussão do texto "Química na Sociedade”. A discussão se deu a partir da questão: "Após a leitura do texto podemos dizer que a Química está em todos os lugares?”. Algumas respostas obtidas foram:

\footnotetext{
Aluno 1: "Ficou mais claro! Eu nunca tinha pensado nisso pois sempre ouvi dizer que a química era coisa daqueles cientistas malucos que ficam fazendo aqueles negócios no laboratório"

Aluno 5: "Na verdade eu nunca tinha lido algo sobre isso, mas faz todo sentido o que li".

Aluno 8: "Ajudou bastante! Porque toda vida eu achava que a química era algo ruim".

Aluno 20: "Sim. Eu achando que química era outra coisa".
}

Fazendo uma análise das respostas, nota-se que a leitura do texto foi importante para a aquisição de novas informações. Como descreve Barbosa e colaboradores (2016), a leitura mediada de textos relacionados a química pode favorecer a aproximação dos conteúdos ensinados no ambiente escolar com o cotidiano dos estudantes. Para isso é necessário que os professores recorram a essa estratégia de ensino com mais frequência de modo a desenvolver nos seus alunos a capacidade de leitura e interpretação de conceitos científicos, dentro ou fora do ambiente escolar.

\section{APRESENTAÇÃO, ANÁLISE E EXPOSIÇÃO DAS FOTOGRAFIAS}

A fase de apresentação das fotografias para a turma proporcionou um momento de interpretação, reflexão e análise crítica, uma vez que os alunos perceberam detalhes que 
deram diferentes interpretações para uma mesma imagem, pois detalhes que não chamam a atenção durante a observação do fenômeno ao vivo podem prender nosso olhar diante da fotografia. Por isso, a fotografia pode ser uma ferramenta útil para despertar a atenção de estudantes a determinados fenômenos, ainda mais que os mesmos são participantes ativos deste processo didático.

No total foram apresentadas 13 imagens diferentes. Algumas fotografias produzidas pelos discentes e suas respectivas legendas estão dispostas a seguir.

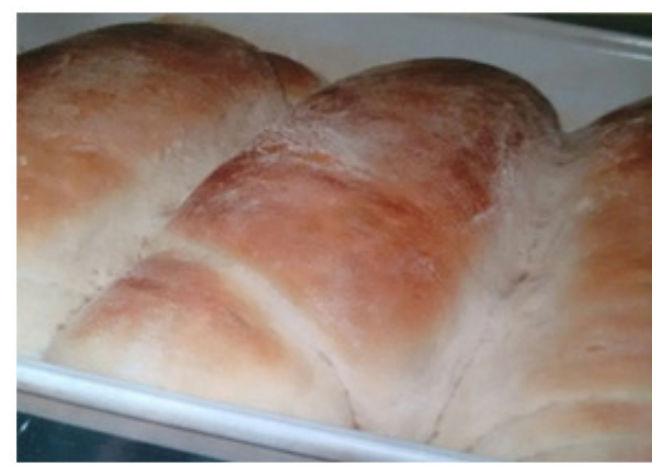

Legenda: A fermentação é responsável pela produção de inúmeros produtos que consumimos diariamente, entre os quais, o mais conhecido é o pão. Ela pode acontecer por meio de elementos naturais ou industrializados. Sua função é encorpar a massa, dar sabor e maciez.

Figura 1 - Fotografia e legenda elaboradas pelos estudantes

Fonte: Acervo pessoal

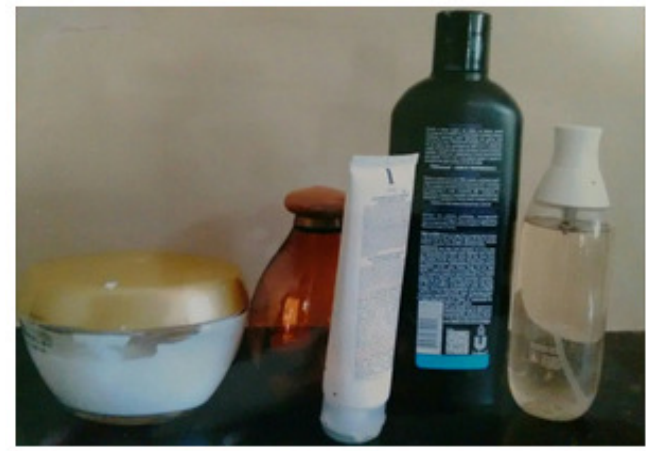

Legenda: A química está presente nos produtos de beleza e seus estudos são fundamentais para a descoberta de novos princípios ativos, que possibilitam a produção de novos produtos, mais eficientes e com diferentes texturas e fragrâncias.

Figura 2 - Fotografia e legenda elaboradas pelos estudantes

Fonte: Acervo pessoal

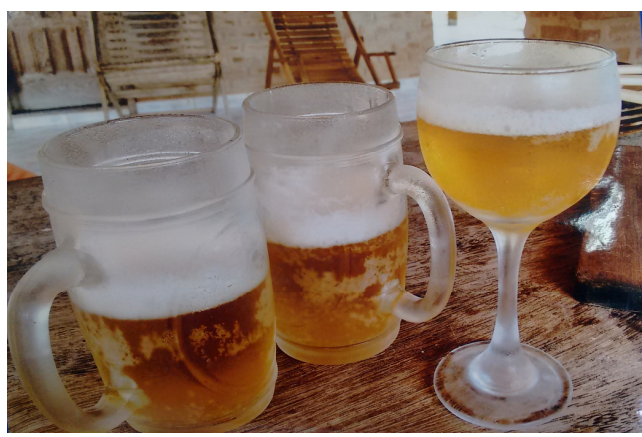

Legenda: A produção de cerveja envolve diversos processos químicos, entre os quais, destacamos a fermentação. A cerveja é uma bebida elaborada com malte de cevada, água, lúpulo e fermento (levedura).

Figura 3 - Fotografia e legenda elaboradas pelos estudantes

Fonte: Acervo pessoal

A medida que as fotografias foram sendo apresentadas pela turma, observou-se que os alunos começaram a interagir de maneira mais evidente. Essa interação entre os estudantes sugere que as imagens são fontes múltiplas de informações e que sua interpretação é singular 
para cada pessoa. Esse debate, oriundo das diferentes percepções dos alunos sugere que "a utilização das imagens fotográficas como material de apoio didático, pode viabilizar uma prática educacional mais direcionada à formação de cidadãos críticos” (SILVA et al., 2017, p.3).

Outro ponto importante relatado pelos alunos se refere a elaboração da legenda que, segundo eles, serviu de estímulo para pesquisar e conhecer um pouco mais sobre o assunto.

Ao término das apresentações, as fotografias foram expostas no mural da escola (Figura 4).

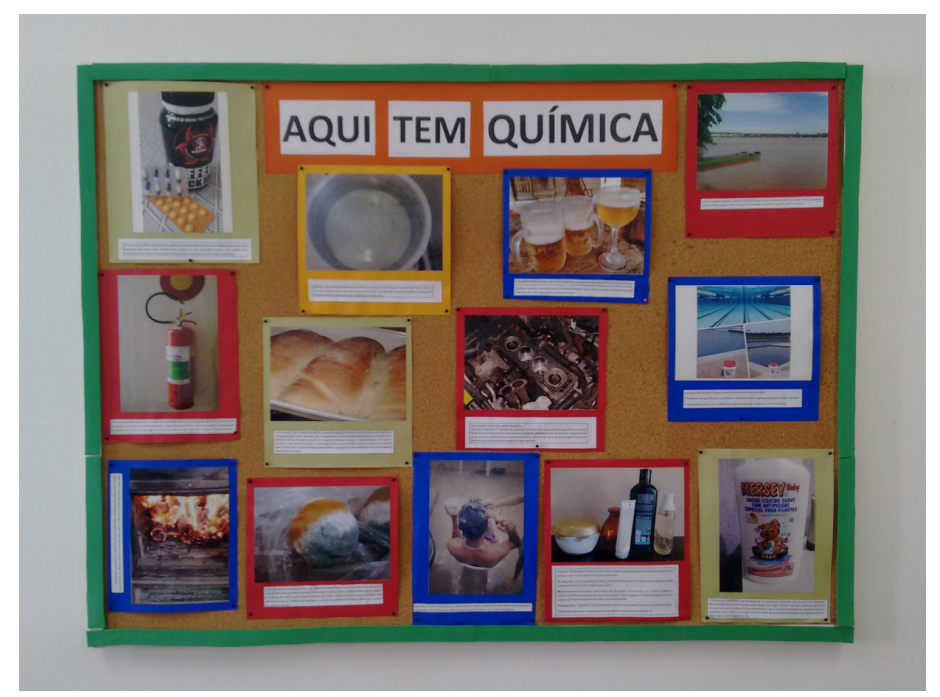

Figura 4 - Exposição das fotografias no mural da escola Fonte: Acervo pessoal

$\mathrm{Na}$ aula seguinte, os 40 estudantes que participaram do projeto foram convidados a responder duas perguntas para avaliação da proposta didática. As perguntas e respostas estão descritas no Quadro 1.

Quadro 1 - Perguntas e respostas utilizadas para avaliar a metodologia de ensino

\begin{tabular}{|l|l|}
\hline \multicolumn{1}{|c|}{ Perguntas } & Respostas \\
\hline 1- Você teve dificuldades para realizar a atividade proposta? Comente. & Sim - (02) \\
Não - (38) \\
\hline $\begin{array}{l}\text { 2- Essa atividade contribui para o seu aprendizado em química? } \\
\text { Comente. }\end{array}$ & Não - (35) \\
\hline
\end{tabular}

Fonte: Acervo pessoal

Analisando as respostas dos alunos, relacionadas a Questão 1, percebe-se que a maioria dos alunos não encontrou grandes dificuldades para desenvolver as atividades propostas. Somente dois participantes apontaram alguma dificuldade, conforme descrito a seguir:

Aluno 21 - "Achei difícil fazer a legenda porque eu poderia falar de diferentes pontos de uma mesma foto".

Aluno 30 - "Só para escrever a legenda".

Em relação a contribuição da metodologia para o aprendizado de química a maioria dos estudantes deram retorno positivo. Dos 40 participantes, apenas 5 apontaram que esse 
Ensino, Saúde e Ambiente - V13 (1), pp. 344-353, Abr. 2020

método de ensino não foi satisfatório para sua aprendizagem, porém nenhum deles justificou sua resposta.

Assim, a proposta conseguiu alcançar seus objetivos uma vez que durante as atividades teve-se a participação ativa dos alunos, promovendo o trabalho em equipe e estimulando a discussão entre os grupos com a troca de informações, configurando a proposta didática como uma alternativa viável ao ensino de química.

\section{CONSIDERAÇÕES FINAIS}

Com o desenvolvimento desse projeto, percebe-se a importância da utilização de metodologias de ensino capazes de desenvolver no educando a capacidade de relacionar o conhecimento científico com seu cotidiano.

No que se refere ao uso da fotografia, notou-se que os resultados foram satisfatórios e possibilitaram uma ampliação e internalização de conceitos relacionados a presença da química no cotidiano. Neste contexto, cabe ao professor desenvolver tais metodologias de modo a envolver os estudantes no processo de ensino-aprendizagem, contribuindo para sua formação como cidadão crítico.

Verifica-se que ainda são poucos os trabalhos que utilizam fotos no ensino de química. Portanto, espera-se que o mesmo possa servir de estímulo para outros docentes.

\section{REFERÊNCIAS}

BARBOSA, A.C; SILVA, N.C; JÚNIOR, C.S; SILVA, L.R.L. Mediação de leitura de textos didáticos nas aulas de química: uma abordagem com foco na matriz de referência do Enem. Revista Ensaio. Belo Horizonte. v. 18. n. 3. p.175-198. set-dez. 2016.

COSTA, E.; SILVA, T. A utilização da produção fotográfica por estudantes do fundamental II, para registros entomológicos. In: XIII Congresso Internacional de Tecnologia da educação, Maceió- Al., p. 1- 13, 2015.

CUNHA, M.B. A Fotografia científica no ensino: considerações e possibilidades para as aulas de química. Química nova na escola. São Paulo- SP, v. 40, n 4, p. 232-240, Novembro, 2018.

DORNELES, E.P. O uso de diferentes metodologias na construção do processo de ensino e aprendizagem em química. In: VIII ENCONTRO DE PESQUISA EM EDUCAÇÃO, 2015, Uberaba - MG. Anais eletrônicos...Disponível em: https://www.uniube.br/eventos/epeduc/2015/completos/18.pdf. Acesso em: 10/05/2018.

FURTADO, I.O. A análise da paisagem através de fotografias tiradas pelos próprios alunos: os possíveis usos para o celular nas aulas de geografia. In: VII CONGRESSO BRASILEIRO DE GEÓGRAFOS, 2014, Vitória-ES. Anais eletrônicos... Disponível em: 
Ensino, Saúde e Ambiente - V13 (1), pp. 344-353, Abr. 2020

http://www.cbg2014.agb.org.br/resources/anais/1/1407205371_ARQUIVO_Artigo_Completo -Ires_Furtado.pdf. Acesso em: 10/05/2018.

GUERRA, E. L. A. Manual pesquisa qualitativa. Belo Horizonte: Anima Educação, 2014, $52 \mathrm{p}$.

LIMA, J.K.F; FIRMINO, M.C; MEDEIROS, L.N; RIBEIRO, E.N.P. O ensino de química: aceitação dos alunos pela disciplina. In: V ENCONTRO NACIONAL DE LICENCIATURAS, 2014, Rio Grande do Norte. Anais eletrônicos... Disponível em: http://enalic2014.com.br/anais/anexos/910.pdf. Acesso em: 07/04/2018.

MESSEDER, J.C; ROCHA, G.S; LEAL, W.S. Uso de fotografia no estudo da tabela periódica. Revista Dynamis. Blumenau, v.25, n.2, p. 205 - 223, 2019.

MOREIRA, M. A. O que é afinal Aprendizagem significativa? Aula Inaugural do Programa de Pós-Graduação em Ensino de Ciências Naturais, Instituto de Física, Universidade Federal do Mato Grosso, Cuiabá, MT, 23 de abril de 2010. Disponível em: http://moreira.if.ufrgs.br/oqueeafinal.pdf. Acesso em 12/05/2018.

SANA, T.C.V; SOUZA, D.D.D; ARROIO, A. O papel das imagens fotográficas no processo de construção do conhecimento em sala de aula de química. Redequim. v 2, n¹, p 5-17, 2016.

SILVA, M.G.V. O uso de fotografias para avaliação da aprendizagem dos conceitos de fenômenos físicos e reações químicas. In: IX Encontro Nacional de Pesquisa em Educação em Ciências, 2013, Águas de Lindóia, SP. Anais eletrônicos... Disponível em:

http://www.nutes.ufrj.br/abrapec/ixenpec/atas/resumos/R0863-1.pdf. Acesso em: 07/04/2018.

SILVA, I.F.F; SANTOS, F.K.S; SILVA, L.L; CANÊJO, V.P. A fotografia como recurso mediático no ensino de geografia: a paisagem urbana em múltiplos olhares e convergências. In: XIII ENCONTRO NACIONAL DE PRÁTICA DE ENSINO EM GEOGRAFIA, 2017, Belo Horizonte. Anais eletrônicos... Disponível em: https://www.ufpe.br/documents/1147022/1148797/Artigo+ENPEG+2017+\%5BITALLO\%5D .pdf/5335d3b9-aff4-4196-bc0d-e9ff3c012e29. Acesso em: 07/04/2018.

\section{SOBRE OS AUTORES}

AUTOR 1. Possui graduação em Farmácia pela Escola Superior São Francisco de Assis e em Pedagogia pelo Centro Universitário Claretiano. É mestre em Ensino na Educação Básica pela Universidade Federal do Espírito Santo. Tem experiência na área de Educação, com ênfase em Educação Especial e Inclusiva. É organizadora dos livros "Práticas inclusivas: saberes, estratégias e recursos didáticos e "Práticas Inclusivas no Ensino Técnico".

AUTOR 2. Possui graduação em Química Industrial e Bacharelado em Química pela Universidade Federal do Rio Grande do Sul. Realizou o doutorado em Química na Universidade Federal do Rio Grande do Sul, com período sanduíche na Universitat Autònoma de Barcelona, sobre a hidroformilação homogênea e bifásica de olefinas e ésteres graxos insaturados. Atualmente desenvolve trabalhos de docência e pesquisa na Universidade Federal do Espírito Santo (campus São Mateus). Membro do corpo docente permanente do Programa de Pós-Graduação em Ensino na Educação Básica da UFES (PPGEEB). As principais áreas 
de atuação são: Uso de materiais bioadsorventes para tratamento do óleo de fritura, biodiesel e efluentes aquosos; Ensino de Química (desenvolvimento de materiais pedagógicos e metodologias diferenciadas; uso de metodologias ativas e formação de professores). 